\title{
Impact of Mechanical Reliability and Production Cost on the Thumb's Four Crossed Bar Mechanisms
}

\author{
Nestor Tsamo, Denis Tcheukam Toko, Pierre Kisito Talla
}

\begin{abstract}
The thumb mechanism of a cybernetic human hand prosthesis is modeled with a one degree of freedom four crossed bar mechanism .The optimization process is carried out with respect to five design criteria which are: structural error due to the bending angle of the second phalanx, mechanical error due to the dimensional tolerances and the clearances at the articulations, Maximum driving torque to counter balance the forces applied at the tip of the thumb's mechanism, strength mechanical reliability of the whole mechanism and production cost of the mechanism. The individual optimization process, gives at each stage, a singular design variable from one design criterion to another. Meanwhile, the introduction of the global production cost to the multiobjective optimization of four criteria and of the five criteria respectively generate the same optimum variables obtained when minimizing simultaneously the four first criteria. Therefore, the mechanical reliability and the production cost of the whole mechanism has a significant effect on the whole process of the mechanism optimization due to the stochastic nature of the trajectory of the cutting tools during the entire manufacturing process.
\end{abstract}

Index Terms - design criteria, mechanical reliability, multiobjective optimization, thumb mechanism.

\section{INTRODUCTION}

A human hand is an amazing complex set of mechanisms with 21 degrees of freedom (DOF); Four (DOF) per finger and five (DOF) for the thumb, which has two phalanges and one metacarpus. See fig. 1 [1] - [4]. The use of prosthesis to replace a missing hand is one of the most fascinating challenges in the rehabilitation protocol because the loss of one hand can significantly affect the level of autonomy and the capability of performing daily living tasks, social activities and trade [5]. State of the art actual commercial prosthesis lack durability adequate cosmetic appearance, affordability and adequate grasping as a humanoid hand [6], [7]. Most prosthesis fail to closely match the user specific anthropometry and have poor aesthetics, which result regularly in abandonment of the device by the amputees [8], [9].

In the rehabilitation protocol usually the adduction/abduction movement is skipped except for the thumb [10], [11].

Nestor Tsamo, Mechanical Engineering Department, College of Technology,University of Buea, P.O. Box 63 Buea, Cameroon. (+237) 650.77.71.23.

Denis Tcheukam Toko, Mechanical Engineering Head of Department, College of Technology, University of Buea, P.O. Box 63 Buea, Cameroon. (+237) 677760861 .

Pierre Kisito Talla, Head of Department of Pysics.University of Dschang P.O.Box 96,Dschang,Cameroon.(+237) 674.78.48.70.
The thumb design of an anthropomorphic prosthetic hand is critical since it accounts for arguably 40 percent of the entire functionality of the human hand [12], [13]. The thumb plays the paramount opposition role on the various grasping mode [14]. In housekeeping and laundry, the grasping mode is dominated at 60 percent by the adducted position of the thumb. Many authors used one DOF four bar mechanism, which allow equal force distribution, less structural grasping error and the trajectory is determined by the finger mechanism to optimize the mechanisms [15]. To obtain the fully functionality of the thumb, one of the best solutions is the use of two D.C Motors; one for flexion and another one for opposition in the four-bar mechanism [16], [17].

The aim of our study is to optimize each mechanism using the objective functions; Structural error and Mechanical error due to the imprecision of the mechanism during the manufacturing processes. In order to study the trustworthy affordable real design of the synthesized mechanism, it is necessary to take into account not only the Production Cost but also the Mechanical Reliability of the whole mechanism to obtain the real design parameters of the optimal mechanism [18].Assuming that the thumb is a particular finger among another in its operating configuration, the mechanism was optimized on the basis of individual optimization in one hand, and multiobjective optimization in another hand [19], [20]. Finally, the multiobjective optimization process will be necessary to evaluate the influence of the said criteria on the prosthesis's independent design variables.

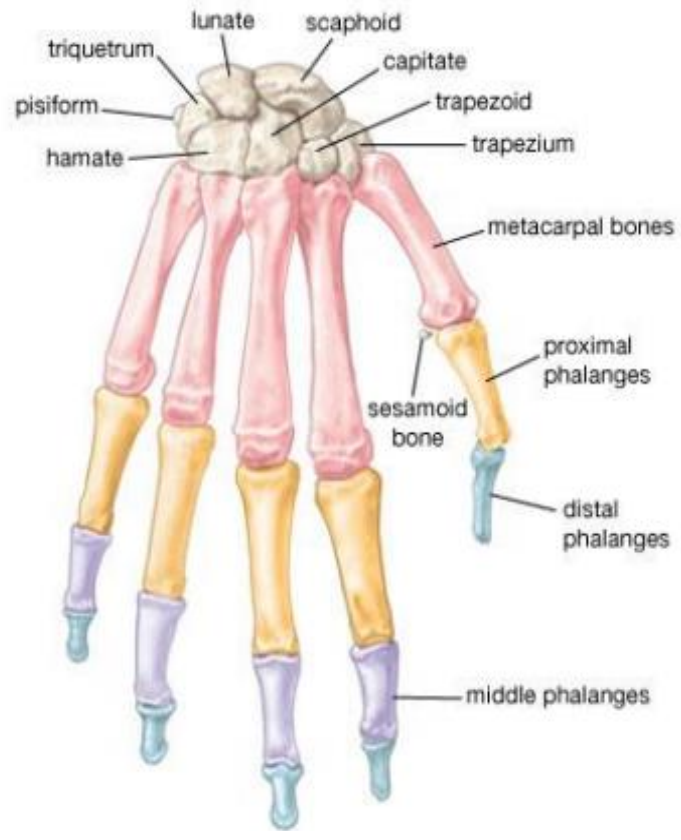

Fig.1: Human hand physiology [4] 


\section{DESCRIPTION AND SYNTHESIS OF THUMB'S MECHANISM}

\section{A. Thumb 's mechanism description}

An articulated planar mechanism consisting of four bar mechanism is used to model a human cybernetic hand, see fig.2. for the thumb [10], [21], with respectively two phalanges P1 and P2 and one metacarpal M1. QM and AM are respectively the fixed bar and the driven one. The bending angle TP1, TP2 and TP3, measured from one phalanx to another, are respectively the bending angles of phalanges $\mathrm{P} 1$, $\mathrm{P} 2$ and P3. The articulated joint between the two first phalanges leads outwards from Eccentricity (EXC) towards the back of the hand which is articulated at B. At the end of the thumb, a grasping force $\mathrm{P}$ is exerted and makes an angle $\theta_{p}$ with the axis of phalanx $\mathrm{P} 2$, with $\mathrm{P} 2$ ' as thumb's effective length.

\section{B. Thumb driving system mechanism parameters}

The partial thumb driving system is shown on fig.3 [22], and consists of a cable connected both to the driving link at the point $\mathrm{T}$ and to the driving pulley at a point whose connection angle is $\rho . x_{T}$ and $y_{T}$, respectively $x_{C}$ and $y_{C}$ are the coordinates of the connection point $\mathrm{T}$ and respectively the coordinates of the center of the pulley. The pulley $\mathrm{C}$ is a backdriving because its bending plane differ from the other fingers.

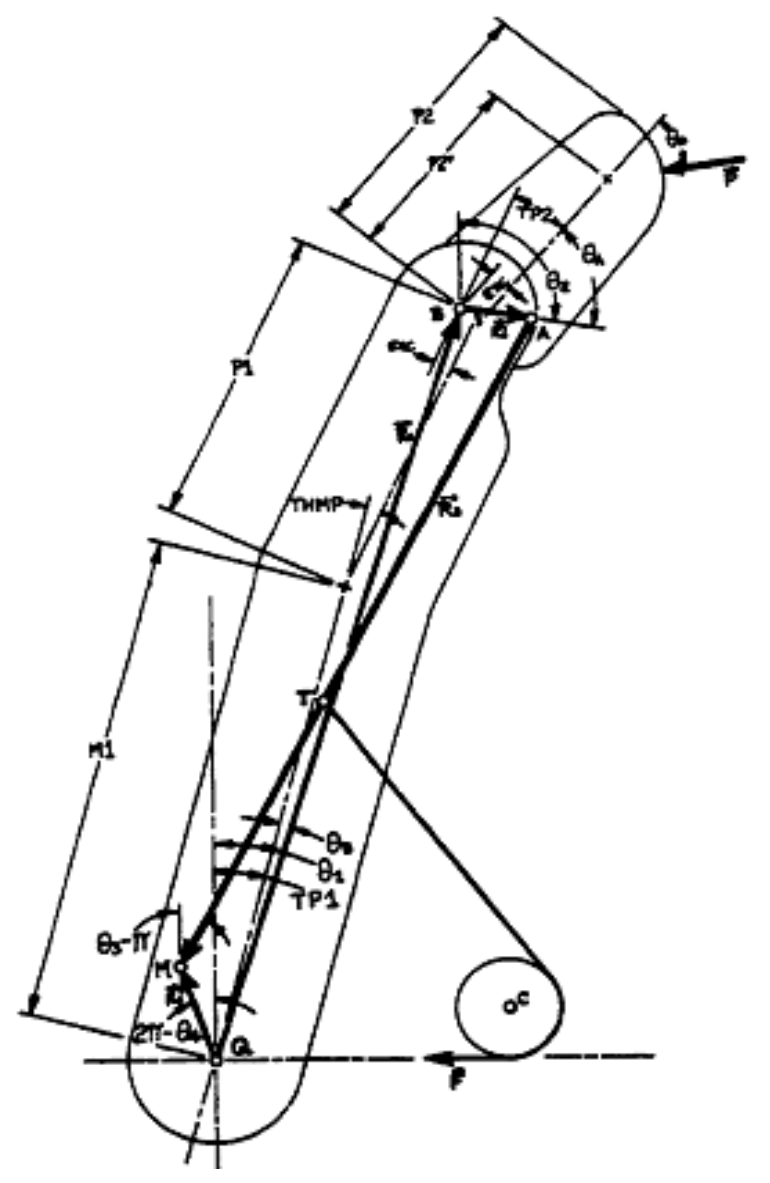

Fig.2: Thumb's parameters [22]
Due to the complexity of the movement perform by this one, two D.C motors are exclusively dedicated to control the bending movement and the adduction/abduction posture [15].

P: applied force with an angle of $\theta_{\mathrm{P}}$ to the axis of the corresponding phalange

P1, P2, P3: lengths of proximal, middle and distal phalanges respectively

P3': Effective length of the distal phalange

$\mathrm{QM}$ and $\mathrm{AM}$ : fixed and driving bar respectively

TP1, $\varphi$ and $\psi$ : Bending angles of phalanges with respect to the plane of the palm

TP2, TP3: Bending angles of P2 and P3 measured from one phalange to another respectively

$\theta_{\mathrm{P}}$ : angle between force at tip of finger with the axis of the phalange

R1, R2, R3 and R4: Lengths of bar 1, 2, 3, and 4 respectively. $\theta_{1}, \theta_{2}, \theta_{3}$ and $\theta_{4}$ : angles of the phalanges of the mechanism with respect to a plane parallel to the plane of the palm

Q: Trapezometacarpal articulation

M1: Thumb metacarpal

P2': operative length of the second phalanx P2

TP1: Bending angle of M1 according to palmar plan

THMP: bending angle of $\mathrm{P} 1$ according to M1 (fixe angle)

$\theta_{A}$ : Angle between second phalanx axis and the various link

$\theta_{B}$ : Angle between M1 and the various link

\section{Mechanism synthesis}

At any mechanism position i, Freudenstein's relation

[3], [23]- [25] between $\theta_{1 \mathrm{i}}$ and $\theta_{2 \mathrm{i}}$ is:

$\mathrm{k}_{1} \cos \left(\theta_{1 \mathrm{i}}-\theta_{4}\right)+\mathrm{k}_{2} \cos \left(\theta_{2 \mathrm{i}}-\theta_{4}\right)-\mathrm{k}_{3}=\cos \left(\theta_{1 \mathrm{i}}-\theta_{2 \mathrm{i}}\right)$

With,

$$
\left\{\begin{array}{l}
\theta_{\mathrm{B}}=\operatorname{Arctg}\left[\frac{\sqrt{\mathrm{P}^{2}+\mathrm{EXC}^{2}} \cdot \sin \left(\mathrm{THMP}-\operatorname{arctg} \frac{\mathrm{EXC}}{\mathrm{P} 1}\right)}{\mathrm{M} 1+\sqrt{\mathrm{P}^{2}+\mathrm{EXC}^{2}} \cdot \cos \left(\mathrm{THMP}-\operatorname{arctg} \frac{\mathrm{EXC}}{\mathrm{P} 1}\right)}\right] \\
\mathrm{r}_{\mathrm{l}}=\frac{\sqrt{\mathrm{P}^{2}+\mathrm{EXC}^{2}} \cdot \sin \left(\mathrm{THMP}-\operatorname{arctg} \frac{\mathrm{EXC}}{\mathrm{P} 1}\right)}{\theta_{\mathrm{B}}}
\end{array}\right.
$$

Where,

$$
\left\{\begin{array}{l}
k_{1}=\frac{r_{4}}{r_{2}} ; k_{2}=\frac{r_{4}}{r_{1}} ; k_{3}=\frac{r_{1}^{2}+r_{2}^{2}-r_{3}^{2}+r_{4}^{2}}{2 r_{1} r_{2}} ; \theta_{1 i}=T P 1_{i}-\operatorname{arctg}\left(\frac{E X C}{P 1}\right) \\
\theta_{2 i}=\theta_{A}+T P 1_{i}+T P 2_{i}
\end{array}\right.
$$

Assuming that $r_{1}, \theta_{A}, \theta_{4}, 7$ positions $T P 1_{i}$ and $T P 2_{i}$ are known, the mechanism synthesis is then performed using the least square method.

\section{Invariable parameters}

Throughout the optimization process, the following values shall remain constant:

- The force at the tip of the fingers is $45 \mathrm{~N}$ with $\theta_{\mathrm{P}}=90^{\circ}$;

- The eccentricity (EXC) is $2 \mathrm{~mm}$; 


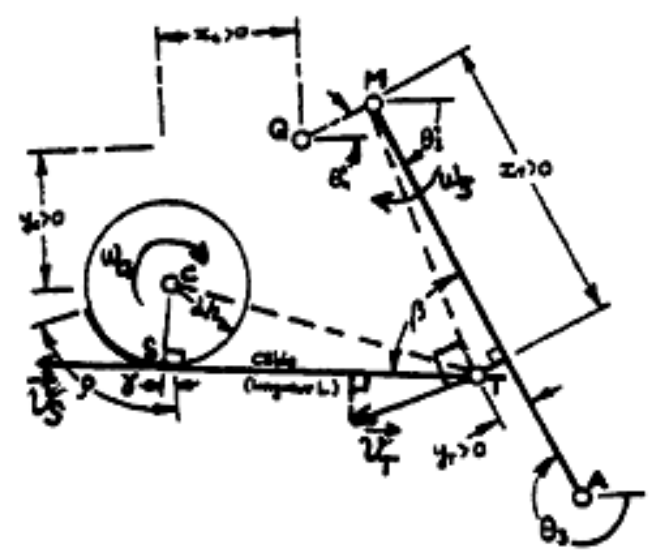

Fig.3: Thumb mechanism's driving system [21]

\section{E. Variable parameters}

Table 1: Design variables bounds for the thumb's mechanism [21]

\begin{tabular}{cccccccc}
\hline$(\mathbf{m m})$ & $\mathbf{r}_{\mathbf{2}}$ & $\mathbf{r}_{\mathbf{4}}$ & $\left.\boldsymbol{\theta}_{\mathbf{4}} \mathbf{(}^{\mathbf{0}}\right)$ & $\mathbf{t}_{\mathbf{m}}$ & $\mathbf{x}_{\mathbf{T}}$ & $\mathbf{y}_{\mathbf{T}}$ & $\mathbf{d}$ \\
\hline $\min$ & 5 & 5 & 360 & 0.794 & 10 & -5 & 10 \\
$\max$ & 15 & 7.5 & 380 & 1.588 & 20 & 5 & 17 \\
\hline
\end{tabular}

The variable parameters are the independent design parameters of the mechanism. They are deduced from the parameters of the modified crossed four-bar mechanism of the thumb in relation to the modified Freudenstein equation from (1) in the section $\mathrm{C}$ above.

$r_{1}=$ length of input bar; $r_{2}=$ length of junction bar;

$r_{3}=$ length of driving bar; $r_{4}=$ length of fixed bar;

$\theta_{4}=$ angle of the fixed bar with respect to a plane parallel to the plane of the palm;

$\theta_{A}=$ angle between the second phalange and the bar of the thumb to which it is referred;

$\theta_{B}=$ angle between metacarpal articulation (M1) and the bar to which it is referred.

Considering the fact that the length of the driven bar $\left(r_{1}\right)$ is fixed, the vector $\mathrm{x}$ of the independent variables of the design is given by:

$$
\begin{aligned}
X & =\left[\mathrm{x}_{1}, \mathrm{x}_{2}, \mathrm{x}_{3}, \mathrm{x}_{4}, \mathrm{x}_{5}, \mathrm{x}_{6}, \mathrm{x}_{7}, \mathrm{x}_{8}, \mathrm{x}_{9}\right]^{\mathrm{T}} \\
& =\left[\theta_{\mathrm{A}}, \mathrm{r}_{2}, \mathrm{r}_{3}, \mathrm{r}_{4}, \theta_{4}, \mathrm{t}_{\mathrm{m}}, \mathrm{x}_{\mathrm{T}}, \mathrm{y}_{\mathrm{T}}, \mathrm{d}\right]^{\mathrm{T}}
\end{aligned}
$$

With $\theta_{\mathrm{A}}=\theta_{2 \mathrm{i}}-\left(\mathrm{TP} 2_{\mathrm{i}}+\mathrm{TP}_{1}+\mathrm{THMP}\right)$

The force $\mathrm{P}$ applied at the end of the thumb is equal to $45 \mathrm{~N}$ and makes an angle $\theta_{\mathrm{P}}=90^{\circ}$ with the phalanx P3 axis. The maximum tension developed in the cable is $F_{T \max }=400 N$. Table 1 gives overall dimensions of thumb's mechanism with DP1, DP2 and WR3 are respectively diameters of phalanges P1 and P2 and width of links.

Table 2: Linear dimensions of thumb's mechanism [22]

\begin{tabular}{cccccccc}
\hline (mm) & DP1 & DP2 & WR3 & P1 & P2 & P3' & EXC \\
& 15 & 13 & 5 & 43.5 & 29 & 13.5 & 2 \\
\hline
\end{tabular}

Table 3: $\mathrm{TP}_{\mathrm{i}}$ angular positions of thumb's mechanism [21]

\begin{tabular}{cccccccccc}
\hline \multicolumn{1}{c}{$\left.\mathbf{(}^{\mathbf{}}\right)$} & $\mathbf{T P 1}_{\mathbf{1}}$ & $\mathbf{T P 1}_{\mathbf{2}}$ & $\mathbf{T P 1}_{\mathbf{3}}$ & $\mathbf{T P 1}_{\mathbf{4}}$ & $\mathbf{T P 1}_{\mathbf{5}}$ & $\mathbf{T P 1}_{\mathbf{6}}$ & $\mathbf{T P 1}_{\mathbf{7}}$ & \\
\hline & & 18 & 29 & 40 & 51 & 61 & 73 & 84 & \\
\hline & & & & & & & & & \\
& & & & & & & & \\
\hline $\mathbf{(}^{\mathbf{0}}$ & $\mathbf{T P 2 1}$ & $\mathbf{T P 1 2}$ & $\mathbf{T P 2 3}$ & $\mathbf{T P 2 4}$ & $\mathbf{T P 2 5}$ & $\mathbf{T P 2 6}$ & $\mathbf{T P 2 7}$ & $\mathbf{T P 3}$ \\
\hline & 14.274 & 18.027 & 24.022 & 32.142 & 41.416 & 55.649 & 75.670 & 30 \\
\hline
\end{tabular}

III. OPTIMIZATION OF THE THUMB'S

\section{MECHANISM}

\section{A. Performance criteria and objective functions}

Five performance criteria are considered in the process of the mechanism's optimization:

- motion posture error or structural error on the bending angle of the second phalange that would be minimized to ensure that the prosthetic finger should pass by the prescribed positions;

- mechanical error on the bending angle of the second phalange, due to dimensional tolerances and clearances on the articulations, that would be minimized;

- maximum shaft driving torque that would be minimized and able to counter-balance a grasping force applied at the end of the middle finger;

- strength reliability of the mechanism that would be maximized to ensure the mechanism strength during grasping, holding or pinching operations;

- manufacturing cost of the mechanism that would be minimized to evaluate its effect on the design variables;

B. Objective function related to the structural error on bending angle TP2: $f_{I}(x)$

$f_{1}(x)=\frac{1}{6} \sum_{i=1}^{7}\left(\theta_{2 i c}-\theta_{2 i d}\right)^{2}$

(6)

where, $\theta_{2 \mathrm{id}}=\theta_{\mathrm{A}}+\mathrm{TP} 1_{\mathrm{i}}+\mathrm{TP} 2_{\mathrm{i}}=\mathrm{x}_{1}+\mathrm{TP} 1_{\mathrm{i}}+\mathrm{TP} 2_{\mathrm{i}}$ is the desired angle and $\theta_{2 \text { ic }}$ the computed or real angle.

\section{Objective function related to the mechanical error on bending angle TP2: $f_{2}(x)$}

$f_{2}(x)=\frac{1}{6} \sum_{i=1}^{7}\left(\Delta \theta_{2 i}\right)^{2}$

with $\Delta \theta_{2 i}=3 \sigma_{\theta_{2 i}}$ where standard deviation is:

$\sigma_{\theta_{2 i}}=\sqrt{2 \sum_{j=1}^{10}\left(\frac{\partial \theta_{2 i}}{\partial a_{J}} \sigma_{a_{J}}\right)^{2}}$ 


$$
=0.001 \sqrt{2\left[\left(\frac{\partial \theta_{2 i}}{\partial r_{1}} r_{1}\right)^{2}+\sum_{j=1}^{9}\left(\frac{\partial \theta_{2 i}}{\partial x_{j}} x_{j}\right)^{2}\right]}
$$

with $\sigma_{a_{J}}=0.001 a_{J}$

\section{Objective function related to the maximum shaft driving torque: $f_{3}(x)$}

Assuming that frictional forces at joints are negligible, $\mathrm{f}_{3}(\mathrm{x})=\max \left(\mathrm{M}_{\mathrm{P}}\right)$ with

$$
M_{P}=\frac{M_{M} d}{2\left(x_{T} \sin \beta+y_{T} \cos \beta\right)}=\frac{x_{9} M_{M}}{2\left(x_{7} \sin \beta+x_{8} \cos \beta\right)}
$$

MP is the driving torque applied to the shaft while MM is torque reduced to point $\mathrm{M}$ of the driving bar [26].

\section{$F$. Objective function related to the strength reliability of the mechanism: $f_{4}(x)$}

The assembly drawing of the thumb's mechanism is represented on Fig.4 bellow.

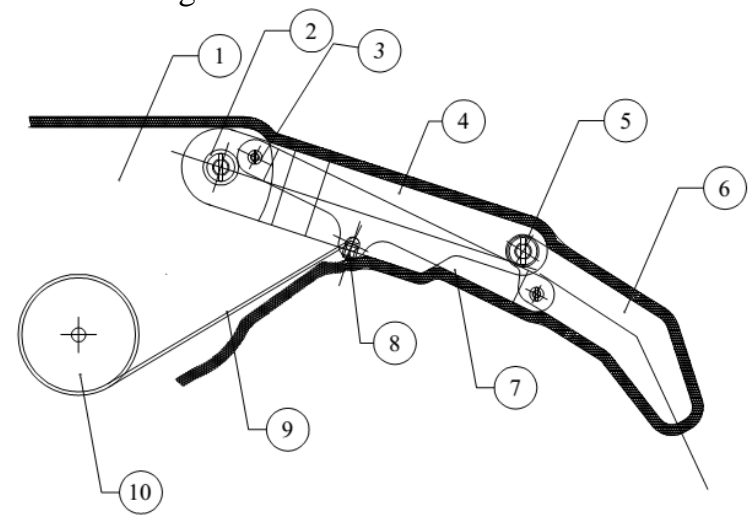

Fig. 4: Assembly drawing of the thumb
1. Palmer frame
6. Junction bar
2. Guiding screw 01
7. Driving bar
3. Guiding screw 02
8. Pressure screw
4. Involved bar
9. Cable
5. Guiding screw 03
10. Pulley

The assembly drawing of the thumb (fig.4) is done according to parameters of the mechanism described in section D and taking into account the width WR3 of each link, the diameters DP1 of the first phalanx and DP2 of the second phalanx.

Since the failure of any link causes the breakdown of the whole mechanism, the across-four bar mechanism is comparable to a system made up of three main components assembled in a serial configuration. Therefore, its mechanical reliability is the product of the reliability of driven, junction and driving bars R1, R2, R3 given by the mathematical expression $\mathrm{f}_{4}(\mathrm{x})=\mathrm{R} 1 . \mathrm{R} 2 . \mathrm{R} 3$. The mechanical reliability of any element is $\mathrm{R}=\left[1-\left(\frac{1.29}{|\mathrm{u}|}\right)^{7.8125}\right] \quad$ [26]. Assuming that the maximum stress $\rho$ induced in a bar and the strength $S$ of material used are lognormally distributed, the statistical parameter is $\mathrm{u}=-\frac{\overline{\ln \rho}-\ln S}{\sqrt{\sigma_{\ln \rho}^{2}+\sigma_{\ln S}^{2}}}[18]$ where

$\overline{\ln a}=\ln \bar{a}-0.5 \sigma_{\ln a}^{2}, \quad \sigma_{\ln a}^{2}=\ln \left[\left(\frac{\sigma_{a}}{a}\right)^{2}+1\right]$,

$\sigma_{a}=0.001\left[\sqrt{2\left(\left(\frac{\partial a}{\partial r_{1}} r_{1}\right)^{2}+\sum_{j=1}^{9}\left(\frac{\partial a}{\partial x_{J}} x_{J}\right)^{2}\right)}\right]$

$\bar{a}$ is the mean value of a, $\overline{\sigma_{a}}$ is the standard deviation of stress or strength a. Using the maximum shear theory, $\rho=\tau_{\max }$ is the maximum shear stress induced in element and $\mathrm{S}=S_{y} / 2$, where $S_{y}=1345 \mathrm{MPa}$ is the yield strength of material used. The maximum shear stress $\rho$ induced in each element is determined from the free body diagram of each bar:

- junction bar $A B$ (fig.3):

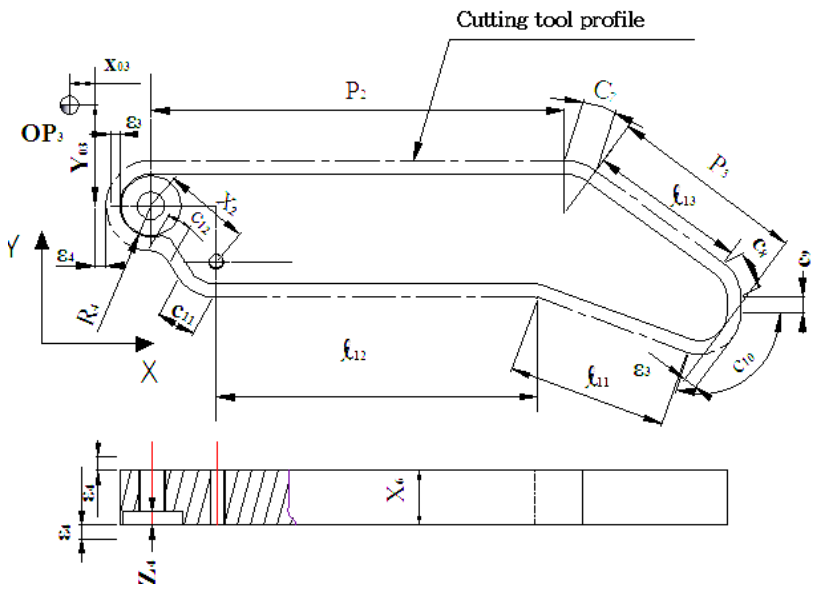

Fig.5: Free body diagram of junction bar AB

$$
\begin{gathered}
\rho_{2}=\tau_{\max 2}=\frac{\left|\sigma_{x^{\prime}}\right|}{2}=\frac{1}{2 t_{m} D P 2}\left(|N|+\frac{6\left|M_{f \max }\right|}{D P 2}\right) \text { with; } \\
N=-P\left[\cos \theta_{P} \cos (\psi-\phi)-\sin \theta_{P} \sin (\psi-\phi)\right] \\
\text { and }, \\
M_{f \max }=-P\left[P_{3}^{\prime} \sin \theta_{P}+P_{2}\left(\cos \theta_{P} \sin (\psi-\phi)\right.\right. \\
\left.\left.\quad+\sin \theta_{P} \cos (\psi-\phi)\right)\right] \\
\mathrm{F}_{\mathrm{BX}}=\frac{\mathrm{E}_{7}}{\mathrm{E}_{1}} ; \mathrm{F}_{\mathrm{BY}}=\mathrm{E}_{7} ; \mathrm{F}_{\mathrm{AX}}=\mathrm{F}_{\mathrm{BX}}+\mathrm{E}_{2} ; \mathrm{F}_{\mathrm{AY}}=\mathrm{F}_{\mathrm{BY}}-\mathrm{E}_{3} \\
\mathrm{E}_{1}=\operatorname{tg}_{1} ; \mathrm{E}_{2}=\mathrm{P}_{\mathrm{x}}=-\mathrm{P}_{\cos \left(\theta_{\mathrm{P}}+\psi\right) ;} \\
\mathrm{E}_{3}=\mathrm{P}_{\mathrm{y}}=\mathrm{P}_{\sin }\left(\theta_{\mathrm{P}}+\psi\right) ; \mathrm{E}_{4}=\mathrm{r}_{2} \sin \theta_{2} ; \\
\mathrm{E}_{5}=\mathrm{r}_{2} \cos \theta_{2} ; \mathrm{E}_{7}=\mathrm{E}_{1} \frac{\mathrm{E}_{6}-\mathrm{E}_{2} \mathrm{E}_{4}-\mathrm{E}_{3} \mathrm{E}_{5} ;}{\mathrm{E}_{4}-\mathrm{E}_{1} \mathrm{E}_{5}}
\end{gathered}
$$$$
\text { with }\left\{\begin{aligned}
\mathrm{E}_{6}= & \mathrm{P}_{\mathrm{y}}\left(\mathrm{P} 3{ }^{\prime} \cos \psi+\mathrm{P} 2 \cos \phi-\mathrm{EXC} \sin \phi\right) \\
& +\mathrm{P}_{\mathrm{x}}\left(\mathrm{P} 3^{\prime} \sin \psi+\mathrm{P} 2 \sin \phi+\mathrm{EXC} \cos \phi\right)
\end{aligned}\right.
$$ 
- driven bar QB (fig.6):

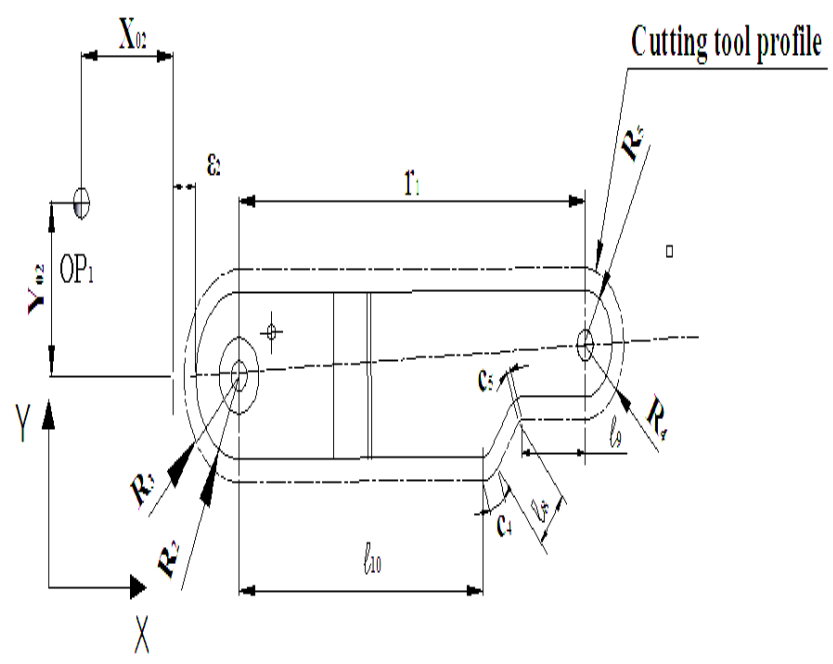

$\rho_{1}=\tau_{\max 1}=\frac{\left|\sigma_{x^{\prime}}\right|}{2}=\frac{\sqrt{\mathrm{F}_{\mathrm{BX}}^{2}+\mathrm{F}_{\mathrm{BY}}^{2}}}{2 \mathrm{t}_{\mathrm{m}} \mathrm{DP} 1}$

\section{- driving bar AM (fig. 5)}

$$
\begin{aligned}
& \rho_{3}=\tau_{\max 3}=\frac{\left|\sigma_{\mathrm{X}^{\prime}}\right|}{2} ; \\
& \text { if } \mathrm{F}_{M X^{\prime}} \leq \mathrm{F}_{A X^{\prime}} \text {, then } \rho_{3}=\left\{\begin{array}{l}
\frac{1}{2 \mathrm{t}_{\mathrm{m}} \mathrm{WR} 3}\left(\mathrm{~F}_{\mathrm{AX}}+\frac{6\left|\mathrm{M}_{\mathrm{fmax}}\right|}{\mathrm{WR} 3}\right) \\
=\frac{1}{2 \mathrm{x}_{6} \mathrm{WR} 3}\left(\mathrm{~F}_{\mathrm{AX}}+\frac{6\left|\mathrm{M}_{\mathrm{fmax}}\right|}{\mathrm{WR} 3}\right)
\end{array}\right. \\
& \text { if } \mathrm{F}_{\mathrm{MX}^{\prime}} \geq \mathrm{F}_{\mathrm{AX}} \text {, then, }\left\{\begin{array}{l}
\frac{-1}{2 \mathrm{t}_{\mathrm{m}} \mathrm{WR} 3}\left(\mathrm{~F}_{\mathrm{MX}}+\frac{6\left|\mathrm{M}_{\mathrm{fmax}}\right|}{\mathrm{WR} 3}\right) \\
=\frac{-1}{2 \mathrm{x}_{6} \mathrm{WR} 3}\left(\mathrm{~F}_{\mathrm{MX}}{ }^{\prime}+\frac{6\left|\mathrm{M}_{\mathrm{fmax}}\right|}{\mathrm{WR} 3}\right)
\end{array}\right.
\end{aligned}
$$

with,

$$
\begin{aligned}
& \left|M_{f \max }\right|=x_{T}\left|F_{M Y^{\prime}}\right|=x_{7}\left|F_{M Y^{\prime}}\right| \text { if }\left\{\begin{array}{c}
\left(y_{T} \leq 0 \text { and } F_{M Y^{\prime}} \leq 0\right) \\
\text { or }\left(y_{T} \geq 0 \text { and } F_{M Y^{\prime}} \geq 0\right)
\end{array}\right. \\
& \left|M_{f \max }\right|=x_{T}\left|F_{M Y^{\prime}}\right|+\left|y_{T}\right| F_{T} \cos \beta=x_{7}\left|F_{M Y^{\prime}}\right|+\left|x_{8}\right| F_{T} \cos \beta \\
& \text { if }\left(y_{T} \leq 0 \text { and } F_{M Y^{\prime}} \geq 0\right) \text { or }\left(y_{T} \geq 0 \text { and } F_{M Y^{\prime}} \leq 0\right) \\
& F_{T}=\frac{-r_{3} F_{A Y^{\prime}}}{\left(x_{T} \sin \beta+y_{T} \cos \beta\right)}=\frac{-r_{3} F_{A Y^{\prime}}}{\left(x_{7} \sin \beta+x_{8} \cos \beta\right)} ; \\
& \left\{\begin{array}{l}
F_{M Y^{\prime}}=-F_{T} \sin \beta-F_{A Y^{\prime}} ; \\
F_{M X^{\prime}}=F_{T} \cos \beta-F_{A X^{\prime}} ; \\
F_{A X^{\prime}}=F_{A X} \cos \theta_{3}^{\prime}+F_{A Y} \sin \theta_{3}^{\prime} ; \\
F_{A Y^{\prime}}=F_{A Y} \cos \theta_{3}^{\prime}-F_{A X} \sin \theta_{3}^{\prime} .
\end{array}\right.
\end{aligned}
$$

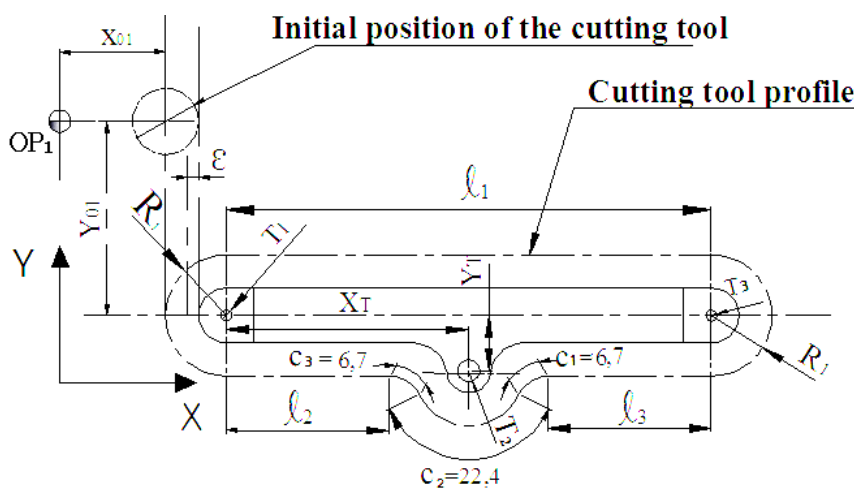

Fig.7: Free body diagram of driving bar AM

\section{G. Objective function related to the global manufacturing cost: $f_{5}(x)$}

\section{Basic assumptions}

- Stainless steel pieces have overall fixed dimensions $2 \times 5 \times L$ and $2 \times 11.5 \times L$ where $\mathrm{L}$ is the length;

- Unit manufacturing cost is expressed in terms of manufacturing time and machine tool hourly cost;

- Because of the programmable machine tool used, machine hourly cost is constant;

- Unit manufacturing costs of machining operations such as turning, drilling, boring, facing and undercutting are Each manufacturing dimension is obtained in only one final operation;

- Machining linear velocity $\mathrm{V}$ is in $\mathrm{m} / \mathrm{min}$;

- Tools store room is equipped with necessary cutting tools used on the programmable machine tool;

- Thermal deformations of the set; machine-tools, working piece and tools are stabilized.

\section{Global manufacturing cost}

The present economic constraints impose to the enterprises of production, the maximal profit that is the production at a minimal cost and at a minimal time [27], [28]. The advanced methods of machining as the use of the Manufacturing Computer Aided Design, improved the productivity of the machining operation meaningfully. The prostheses are manufactured in very small mass production set, therefore, the Manufacturing Computer Aided Design is appropriate for this purpose [29].

Let's consider:

$\mathrm{C}_{\mathrm{g}}$ : The global Manufacturing Cost of across four-bar mechanism ;

$\mathrm{C}_{(\mathrm{i})}$ : The global Manufacturing Cost of the $i^{\text {th }}$ bar of the structure of the mechanism, where $\mathrm{i}=1,2,3$ which corresponds respectively to the involved bar, driving bar and junction bar ; $\mathrm{C}_{\mathrm{u}(\mathrm{ij})}$ : The Manufacturing unitary cost of the $\mathrm{j}^{\text {th }}$ Manufacturing operation on the $\mathrm{i}^{\text {th }}$ bar of the mechanism, where $j=1,2,3,4,5$ corresponding respectively to facing milling, lateral milling, drilling, counter boring and tapping ;

$\mathrm{D}_{(\mathrm{ij})}$ : Cutting tools used relatively at $\mathrm{i}^{\text {th }}$ bar and $\mathrm{j}^{\text {th }}$ Manufacturing operation (Milling cutter 2 cuttings $\emptyset 20$, cutter 2 cuttings $\emptyset 6$, Drill $\emptyset 2$, Drill $\emptyset 4$, piloting Milling cutter to counter boring $\emptyset 2 \times 6$ and Machining tapping M2. 
$\mathrm{L}_{(\mathrm{ij})}=\mathrm{L}_{\mathrm{s}(\mathrm{ij})}=\mathrm{L}_{\mathrm{c}(\mathrm{ij})}=\mathrm{L}_{\mathrm{p}(\mathrm{ij})}=\mathrm{L}_{l(\mathrm{ij})}=\mathrm{L}_{\mathrm{t}(\mathrm{ij})}$ :

Tools trajectories relatively to the facing milling, lateral milling, drilling, counter boring and tapping of the the $i^{\text {th }}$ bar of the mechanism and the $\mathrm{j}^{\text {th }}$ Manufacturing operation;

$\mathrm{OP}_{(\mathrm{i})}=2\left(\mathrm{X}_{0(\mathrm{i})}+\mathrm{Y}_{0(\mathrm{i})}\right)=\mathrm{XY}_{(\mathrm{i})}$ : Starting Machine program = Starting Piece program of the $\mathrm{i}^{\text {th }}$ bar of the mechanism;

$\mathrm{V}, \mathrm{N}, \mathrm{f}, \mathrm{k}, \mathrm{C}$ : respectively linear speed, mass-production set, frequence in turn per tooth, Taylor constant function of material of the cutting tool, Taylor constant function of material of the working piece (NF E 66-505);

$\mathrm{T}_{1}, \mathrm{~T}_{2}, \mathrm{~T}_{3}$ : Holes 1,2 , and 3;

A, F, R, L, E, S: respectively technical amortization, financial expenses, maintenance expenses and of repair, expenses of local or of clutter, expenses of energy and wage costs and social.

$\mathrm{C}_{\mathrm{m}}$ : hourly machine cost (Advanced Manufacturing Computer Aided Design)

$\mathrm{C}_{\mathrm{s}}$ : Cost cutting tools;

$\mathrm{C}_{\mathrm{p},}, \mathrm{C}_{\mathrm{T}}, \mathrm{C}_{\mathrm{Tm}}, \mathrm{C}_{\mathrm{o}}$ : respectively sum of the expenses related directly to the preparation, cutting duration, out of cutting time and the cutting tool;

Ap: global rate of exploitation of the preparation section, general expenses and labour;

\section{Expression of the unit cost of machining $\left(\mathrm{C}_{\mathrm{u}(\mathrm{ij})}\right)$}

The production to the minimal cost and to the maximal profit called on the mathematical models translating the laws of wear of the tools according to the cutting times also named simplified Taylor's law [28]. The Manufacturing unitary cost of the $\mathrm{j}^{\text {th }}$ Manufacturing operation on the $\mathrm{i}^{\text {th }}$ bar of the mechanism is $\mathrm{C}_{\mathrm{u}(\mathrm{ij})}=\mathrm{C}_{\mathrm{p}}+\mathrm{C}_{\mathrm{T}}+\mathrm{C}_{\mathrm{Tm}}+\mathrm{C}_{0}$ with

$$
\begin{aligned}
& \left\{\begin{array}{l}
C_{p}=\frac{T s}{N} \times \frac{A p}{60} \\
C_{T}=\frac{C_{m}}{60} \times \frac{L_{(i j)} \times \pi \times D_{(i j)}}{10^{3} \times V \times f} \\
C_{T m}=\frac{C_{m}}{60} \times\left(\sum_{j=1}^{3} T_{j}+T_{t m}\right)
\end{array}\right. \\
& \left\{\begin{array}{l}
C_{o}=C_{S}\left(\frac{L_{(i j)} \times \pi \times D_{(i j)}}{10^{3} \times f \times C^{-K}} V^{-K-1}-\frac{1}{N}\right) \\
C_{m}=A+F+R+L+E+S
\end{array}\right.
\end{aligned}
$$

The final expression of the cost of a machining pass (Turning, drilling, milling...) is:

$$
\begin{aligned}
C_{u(i j)} & =C_{F}+\pi L_{(i j)} D_{(i j)} M \quad \text { with }, \\
M & =\left[\left(\frac{C_{m}}{6 \times 10^{4} \times V \times f}\right)+\left(\frac{C_{S}}{10^{3} \times f \times C^{-K}} V^{-K-1}\right)\right] \\
C_{F} & =C_{p}+C_{T_{m}}-\frac{C_{S}}{N}
\end{aligned}
$$

\section{Manufacturing cost of the junction bar}

Fig. 5 shows the manufacturing drawing of junction bar. It is manufactured in four basic operations: facing milling $\mathrm{L}_{\mathrm{s}(21)}$, lateral milling $\mathrm{L}_{\mathrm{c}(22)}$, drilling $\mathrm{L}_{\mathrm{p}(23)}$, and counter boring $\mathrm{L}_{l(24)}$.
The unit manufacturing cost related to each of these operations are:

$$
\begin{aligned}
& C_{u(31)}=C_{F}+\pi L_{s(31)} D_{(31)} M ; C_{u(32)}=C_{F}+L_{c(32)} D_{(32)} M ; \\
& C_{u(33)}=C_{F}+L_{p(33)} D_{(33)} M ; C_{u(34)}=C_{F}+L_{l(34)} D_{(34)} M ;
\end{aligned}
$$

Therefore, the manufacturing cost of the junction bar is:

$\mathrm{C}_{3}=4 \mathrm{C}_{\mathrm{F}}+\pi\left(\mathrm{L}_{\mathrm{s}}(31) \mathrm{D}(31)+\mathrm{L}_{\mathrm{c}}(32)^{\mathrm{D}}(32)+\mathrm{L}_{\mathrm{p}}(33) \mathrm{D}^{\mathrm{D}}(33)+\mathrm{L}_{1}(34) \mathrm{D}(34)\right) \mathrm{M}$ (12)

\section{Manufacturing cost of the driving bar}

Fig. 7 shows the manufacturing drawing of driving bar. The trajectories of the cutting tools are established according to the working drawings. This bar $\mathbf{1}$ is manufactured in four basic operations: facing milling $\mathrm{L}_{\mathrm{s}(11)}$, lateral milling $\mathrm{L}_{\mathrm{c}(12)}$, grilling $\mathrm{L}_{\mathrm{p}(13)}$, counter boring $\mathrm{L}_{l(14)}$. The unit manufacturing cost related to each of these operations are:

$$
\begin{aligned}
& C_{u(11)}=C_{F}+\pi L_{s(11)} D_{(11)} M ; C_{u(12)}=C_{F}+L_{c(12)} D_{(12)} M ; \\
& C_{u(13)}=C_{F}+L_{p(13)} D_{(13)} M ; C_{u(14)}=C_{F}+L_{l(14)} D_{(14)} M ;
\end{aligned}
$$

Therefore, the manufacturing cost of the driving bar is:

$\left.C_{1}=4 C_{F}+\pi\left(L_{s(11)} D(11)+L_{c}(12)^{D(12)}+L_{p}(13)^{D(33)}+L_{l}(14)\right)^{D(14)}\right){ }_{M}$ (13)

\section{Manufacturing cost of the driven bar}

Fig. 6 shows the manufacturing drawing of driven bar. It is manufactured in five basic operations: facing milling $\mathrm{L}_{\mathrm{s}(21)}$, lateral milling $\mathrm{L}_{\mathrm{c}(22)}$, drilling $\mathrm{L}_{\mathrm{p}(23)}$, counter boring $\mathrm{L}_{l(24)}$, tapping $\mathrm{L}_{\mathrm{t}(25)}$. The unit manufacturing cost related to each of these operations are:

$\left\{\begin{array}{l}C_{u(21)}=C_{F}+\pi L_{s(21)} D_{(21)} M ; C_{u(22)}=C_{F}+L_{c(22)} D_{(22)} M ; \\ C_{u(23)}=C_{F}+L_{p(23)} D_{(23)} M ; C_{u(24)}=C_{F}+L_{l(24)} D_{(24)} M ; \\ C_{u(25)}=C_{F}+L_{t(25)} D_{(25)} M ;\end{array}\right.$

Therefore, the manufacturing cost of the driven bar is:

$$
C_{2}=5 C_{F}+\pi\left(\begin{array}{l}
L_{s(21)} D_{(21)}+L_{c(22)} D_{(22)}+L_{p(23)} D_{(33)} \\
+L_{l(24)} D_{(24)}+L_{l(25)} D_{(25)}
\end{array}\right) M
$$

\section{Global manufacturing cost of the mechanism Cg}

The global manufacturing cost of the mechanism is

$C_{g}=C_{1}+C_{2}+C_{3}=13 C_{F}+\pi M \times L D$

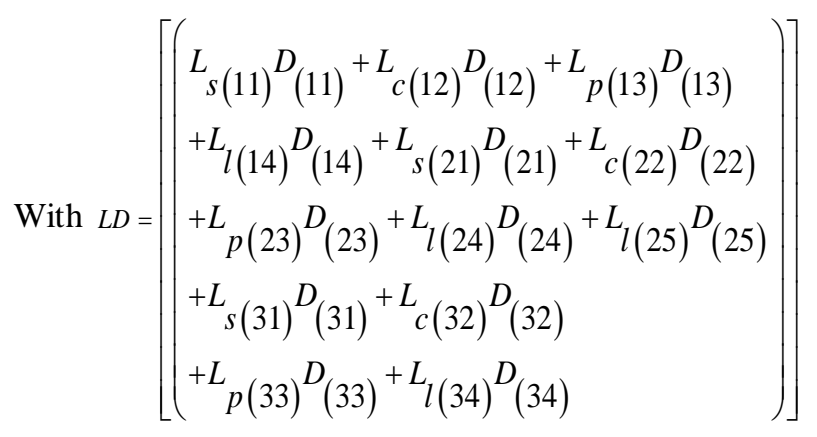

$[18]$ 
Table 5: Optimum design variables

\begin{tabular}{llllllllll}
\hline & $\begin{array}{l}\mathbf{F}_{\mathbf{1}}(\mathbf{\Delta} \mathbf{T P 2}) \\
\mathbf{1 0}^{-6}\left({ }^{\circ}\right)\end{array}$ & $\begin{array}{l}\mathbf{F}_{2}(\mathbf{\Delta T P 2})_{\mathbf{M e c h}} \\
\left({ }^{\circ}\right)\end{array}$ & $\begin{array}{l}\mathbf{F}_{\mathbf{3}} \mathbf{M}_{\mathbf{M A X}} \\
(\mathbf{N m m})\end{array}$ & $\begin{array}{l}\mathbf{F}_{\mathbf{4}} \mathbf{M}_{\mathbf{C O S T}} \\
(\mathbf{U S} \mathbf{)})\end{array}$ & $\mathbf{F}_{\mathbf{5}}$ & $\mathbf{F 6}$ & $\mathbf{F 7}$ & $\mathbf{F 8}$ & $\mathbf{F 9}$ \\
\hline $\mathrm{x}_{1}\left({ }^{\circ}\right)$ & 65.0351 & 65.0354 & 56.9923 & 61.2194 & 87.3142 & 63.3855 & 82.1528 & 82.0630 & 78.1932 \\
$\mathrm{x}_{2}(\mathrm{~mm})$ & 7.5493 & 7.5492 & 9.3495 & 7.2766 & 8.3944 & 5.9964 & 5.0942 & 5.0603 & 5.0603 \\
$\mathrm{x}_{3}(\mathrm{~mm})$ & 73.5694 & 75.5937 & 77.6547 & 75.4232 & 71.6646 & 74.9943 & 36.9875 & 37.0354 & 37.0354 \\
$\mathrm{x}_{4}(\mathrm{~mm})$ & 11.8156 & 11.8154 & 12.8802 & 11.2983 & 11.2842 & 9.5121 & 6.0577 & 6.0197 & 6.0197 \\
$\mathrm{x}_{5}\left({ }^{\circ}\right)$ & 352.4660 & 354.6590 & 360.0000 & 351.668 & 346.5512 & 344.8354 & 375.7396 & 375.6806 & 375.6806 \\
$\mathrm{x}_{6}(\mathrm{~mm})$ & 1.0624 & 1.1157 & 1.2784 & 1.1414 & 1.0824 & 1.1362 & 0.8485 & 0.8517 & 0.8517 \\
$\mathrm{x}_{7}(\mathrm{~mm})$ & 17.0718 & 17.0714 & 15.7538 & 15.0278 & 18.2923 & 15.0012 & 20.0003 & 20.0001 & 20.0001 \\
$\mathrm{x}_{8}(\mathrm{~mm})$ & 5.0000 & 5.0000 & -4.9873 & 5.0000 & -0.2794 & -4.9827 & 5.0002 & 5.0001 & 5.0001 \\
$\mathrm{x}_{9}(\mathrm{~mm})$ & 15.0000 & 15.2874 & 17.0000 & 17.0000 & 14.5945 & 12.6336 & 10.0000 & 10.0000 & 10.0000 \\
\hline & & & & & & & & & \\
\hline
\end{tabular}

Table 6: Optimum objective function values

\begin{tabular}{lrrrrc}
\hline $\mathrm{F}_{\mathrm{i}}(\mathrm{x})$ & $\mathrm{f}_{1}(\Delta \mathrm{TP} 2) 10^{-6}\left({ }^{\circ}\right)$ & $\mathrm{f}_{2}(\Delta \mathrm{TP} 2)_{\text {Mech }}\left({ }^{\circ}\right)$ & $\mathrm{f}_{3} \mathrm{M}_{\text {Max }}(\mathrm{Nmm})$ & $\mathrm{f}_{4} \mathrm{M}_{\text {cost }}(\mathrm{US} \$)$ & \multicolumn{1}{c}{$\mathrm{f}_{5}$} \\
\hline F1 & 3133.4298 & 21.6104 & 2172.2213 & 494.8459 & 0.9995 \\
F2 & 1656.9553 & 347.5135 & 1255.7342 & 501.0021 & 1.0000 \\
F3 & 2310.5795 & 511.4831 & 1255.7342 & 495.2544 & 0.9999 \\
F4 & 3150.5421 & 16.2193 & 1821.7814 & 498.9559 & 1.0000 \\
F5 & 3515.4462 & 19.2052 & 1255.7344 & 499.1203 & 0.9999 \\
F6 & 3133.4125 & 21.6122 & 2172.2236 & 494.8459 & 1.0000 \\
F7 & 3515.4463 & 16.2193 & 1821.1116 & 494.8459 & 1.0000 \\
F8 & 1656.9551 & 21.6162 & 2498.5664 & 494.8459 & 1.0000 \\
F9 & 3133.4018 & 12.4923 & 2943.7501 & 495.2544 & 1.0000 \\
\hline
\end{tabular}

$\mathrm{C}_{\mathrm{g}}$ in USA DOLLARS and the dimensions of all mechanism pieces in millimeters.

While taking into account the dimensional tolerances $\Delta r_{j}$ to the bars, clearances $R c_{j}$ at the articulations and an addimensional variable $\mathrm{k}$ : $\frac{\Delta r_{j}}{3}=\frac{\Delta R c_{j}}{3}=k r_{j}=0.001 r_{j} \Rightarrow \Delta r_{j}=3.10^{-3} r_{j}$

\section{IV.CONSTRAINT FUNCTIONS}

These functions, expressed in terms of design variables are equality constraints $h_{i}(x)=0$ and inequality constraints $\mathrm{g}_{\mathrm{i}}(\mathrm{x}) \leq 0$ according to Matlab optimization toolbox R2015a.

\section{A. Equality constraints}

Using modified Freudenstein's relation and least square method, three equality constraints [30] related to mechanism synthesis with reference to seven positions given in Tables 3 and 4 are obtained. Otherwise, three additional equalities constraints are introduced by the means of security factor related to the design of the whole structure.

\section{B. Inequality constraints}

Eighteen inequality constraints used are respectively related to transmission angle, mechanism dead points, restriction of driving link to be within the phalanges P1

and P2, maximum value of cable tension, maximum driving shaft rotation, cable keeping within palm and finger and connection cable T keeping inside phalanx P1 during a cycle of mechanism's closure.

In addition to design bounds given in table 1 , angle $\theta_{21}$ must to be included between $20^{\circ}$ and $115^{\circ}$; therefore, $\theta_{\mathrm{A}}$ is bounded by $-12.274^{\circ}$ and $82.726^{\circ}$.

\section{OPTIMIZATIONRESULTS, INTERPRETATION AND DISCUSSION}

\section{A. Optimization process}

The thumb was the most difficult fingers to optimize either because of their slow convergence towards the optimal solution, or because of the difficulty in obtaining an adequate starting point making it possible to converge towards the optimal solution.

In order to validate the results obtained, a minimum of three starting points were used and, each single objective function $\mathrm{f} 1(\mathrm{x}), \mathrm{f} 2(\mathrm{x}), \mathrm{f} 3(\mathrm{x}), \mathrm{f} 4(\mathrm{x})$ and $\mathrm{f5}(\mathrm{x})$, subjected to four equality and eighteen inequality constraints, were optimized, taking into account the design variables bounds, by the means of a nonlinear programming algorithm developed in Matlab optimization toolbox R2015a. [31] 
For the multi objective optimization of more than two criteria, $f 6(x), f 7(x), f 8(x)$ and $f 9(x)$, the vector of weighting coefficients $\mathbf{W}$ is such as $\mathrm{W}=$ abs (goal), indicating the absolute value of the vector of the objectives fixed to achieve the "goal". This choice has the advantage to guarantee the same percentage of achieving the objectives for all the active constraints or active objective functions.

The convergence criteria values on the design variables $\mathrm{x}_{\mathrm{i}}$, the objective functions $\mathrm{f}_{\mathrm{i}}$ and the constraints $\mathrm{g}_{\mathrm{i}}$ are respectively equal to $10^{-7}, 10^{-9}$, and $10^{-13}$.

\section{B. Interpretation}

Optimal design variables of the mechanism of the thumb are presented on table 5. Furthermore, we used the minimization function with constraints

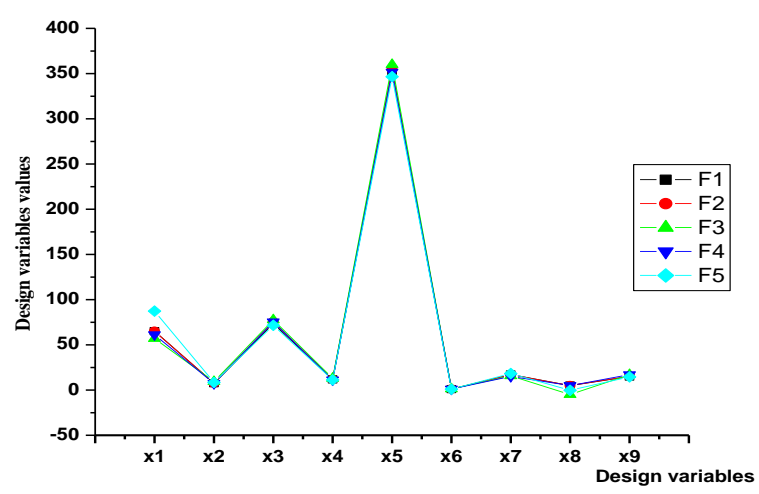

Fig. 8: Optimum values of single objective functions

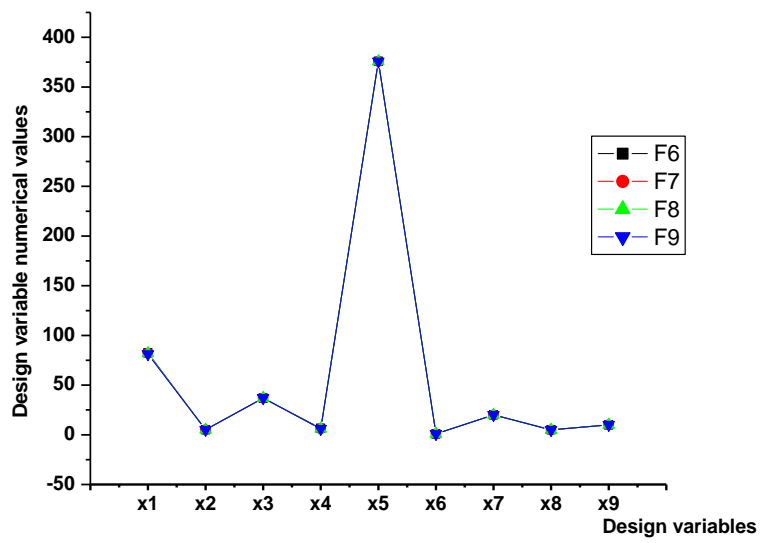

Fig. 9: Optimum values of multiobjective functions

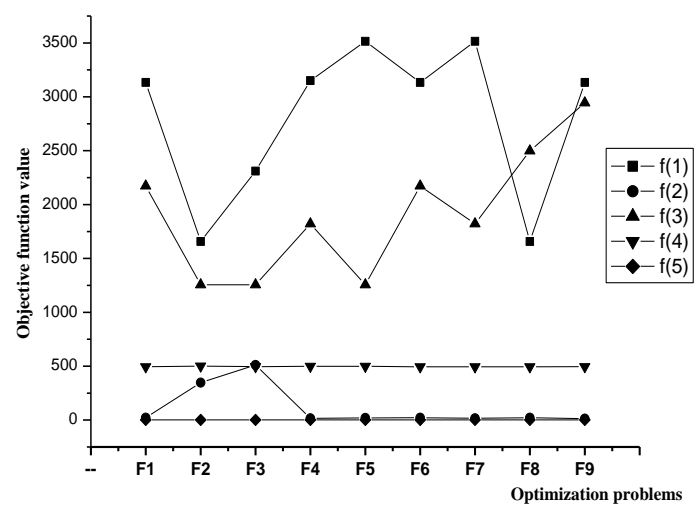

Fig. 10: Optimum values of all objective functions "fmincon" from Matlab optimization Toolbox to optimize all the objective functions used.

Table 6 provide the optimum values of all the objective functions, including multi objective functions. The production cost value and the reliability $\mathrm{R}$ relating to the design of the thumb mechanism, from the start allowed us to make two remarks. The first remark is relative to the reliability $\mathrm{R}$ which, regarding all the criteria is appreciably equal to the unit. This explains the fact that the stochastic nature of the design variables, at the optimal solution, does not practically create any interference between the statistical distribution curve of resistance and that relating to the induced stress. The second remark is related to the minimum production cost, of which the largest design variables values are obtained by the thumb. As shown in table 5, the optimum values of the design variables are different from one single objective function to another. It is also shown that multi objective functions $\mathrm{f} 6, \mathrm{f} 7, \mathrm{f} 8$ and $\mathrm{f} 9$ optimization allowed generally to obtain intermediate values of these extreme design variables. Therefore, strength reliability and mainly production cost have a considerable effect on the optimal design of the thumb's mechanism. In fact, results obtained from multi objective functions $\mathrm{f6}, \mathrm{f} 8$ and $\mathrm{f} 9$ are the same and highlight the production cost role. It can be shown that:

- Optimum values of single objective function optimization are smaller than those obtained by the means of multi objective function optimization, except those related to reliability and production cost which are a little different;

- From individual optimization to multi objective optimization, optimum values of each single function remain the same whereas the fact that design variables related to optimization function $\mathrm{F} 9$ are a little beat different from those of optimization functions F6, F7 and F8.

\section{Discussion}

One noticed that the mechanisms of the fingers are sensitive to the production cost for each criterion considered. This is due to the fact that the design variables obtained during the optimization of the objective function $\mathrm{f}_{\mathrm{i}}$, relative to the reliability $\mathrm{f}_{5}$ are quite different, with some exceptions, of those obtained during the individual minimization of the functions $F_{1}, F_{2}, F_{4}$, and $F_{5}$, respectively to $f_{1}, f_{2}, f_{3}$ and $f_{4}$.

Simultaneous optimization $\mathrm{F}$, of all the criteria made it possible to reduce the mechanical error impact on the nominal and optimal design variables.

Simultaneous optimization F, of all the criteria confer on the thumb the same length of the fixed bar $r_{1}$, and the same angle $\mathrm{K}=360^{\circ}$. This objective function is also conferred to the thumb the same thickness $\mathrm{x}_{6}=\mathrm{t}_{\mathrm{m}}$, of the driving bar $r_{3}$, and the same diameter of the driving pulley $\mathrm{x}_{9}=\mathrm{d}$, during the whole optimization process. 
In addition, the simultaneous optimization of all the criteria $\mathrm{F}$, comes to reduce and even cancel the influence of quadratic error.

In the previous studies, optimal design variables obtained from one multi objective optimization to another are different. In the present work, the production cost, included in any combination of the simultaneous optimization, enabled to obtain the same optimum variables design. In addition, the optimal global production cost of the whole virtual mechanism obtained in this study is about \$ 500 USA Dollars for the thumb mechanism compared to 419 USA Dollars proposed by some authors [18].

\section{CONCLUSION}

The aim of this study was to introduce into the optimization process of the crossed four-bar link mechanism of the hand prosthesis, two new performance criteria, namely the Mechanical reliability and the production cost of the whole mechanism. These criteria were added to those related to the structural error of the bending angle of the second phalanx of the thumb, the mechanical error due to manufacturing imprecision of the working pieces and the maximum driving torque applied to the driving shaft to counter balance the grasping force at the tip of the thumb. This study permits us to confirm that, through the five different optimal mechanisms obtained, each criterion used here generates a singular design, translating its importance in the optimization process. Otherwise, because of the influence of each of these criteria on the mechanism design, their multi objective optimization showed that the mechanical reliability and the production cost, included in any combination of the simultaneous optimization, enabled to obtain about the same optimum variables design. Finally, mechanical reliability is always equal to the unit. That translated the fact that, the constraints induced inside each bar, remain less than the maximum material constraints. In the future work, it will be interesting to introduce in the optimization process of humanoid devices the geometrical tolerances to improve their design

\section{REFERENCES}

[1] I. A. Kapandji, hysiology of the joints : Annoted diagrms of the mechanics of the human joints.Fith edition.Translated by Honore ,L.H.Upper Limb, Churchill Livingstone, 1982.

[2] M. Pelletier and R. Vinet, "Les prothèses de la main. Recherche Bibliographiques.e, École Polytechnique de Montréal," EPM/RT85-28, Montréal, 1985.

[3] R. Robert Vinet, Y. Yves Lozac'h, B. Nicolas and G. Drouin, "Design methodology for a multifunctional hand prosthesis," Journal of Rehabilitation Research and Development, vol. 32, no. 4, pp. 316-324, 1995.

[4] L. Zollo , S. Roccella, E. Guglielmelli, M. Carroza and P. Dario, "Biomechatronic design and control of an antropomorphic artificial hand for prosthetic and robotic applications," IEEE/ASME Transactions on Mechatronics, vol. 12, no. 4, 2007.

[5] I. M. Bullock, J. Z. Zheng, Sara De La Rosa, . C. Guertler and A. M. Dollar, " Grasp Frequency and Usage in Daily Household and Machine Shop Tasks," IEEE TRANSACTIONS ON HAPTICS, vol.
6, no. 3, 2013

[6] J. T. Belter, . J. L. Segil, A. M. Dollar and R. F. Weir, "Mechanical design and performance specifications of anthropomorphic prosthetic hands: A review," The Journal of Rehabilitation Research and Development (JRRD), vol. 50, no. 5, p. 599-618, 2013.

[7] H. Kawasaki and T. Mouri, "Humanoid Robot Hand and its Applied Research," Journal of Robotics and Mechatronics, vol. 31, no. 1, 2019.

[8] J. Zuniga, D. Katsavelis, J. Peck, J. Stollberg, M. Petrykowski, A Carson and C. Fernandez, "Cyborg beast: a low-cost 3d-printed prosthetic hand for children with upper-limb differences," BioMed Central Research Notes.DOI 10,1186/ s 1310, 2015.

[9] E. N. Gama and O. F. Avilés Sánchez, "Anthropomorphic robotic hands: a review," Ingeniería y Desarrollo. Universidad del Norte, vol. 32, no. 2, 2014

[10] L. Y. Chang and Y. Matsuoka, "A Kinematic Thumb Model for the ACT Hand," in Proceedings of the 2006 IEEE International Conference on Robotics and Automation, Orlando, Florida, 2006.

[11] S. M. Engdahl, P. C. Breanne , K. Brian, . D. Alicia and C. A. Chestek, "Surveying the interest of individuals with upper limb loss in novel prosthetic control techniques," Journal of NeuroEngineering and Rehabilitation, no. DOI 10.1186/s12984015-0044-2, 2015.

[12] K. Tomoyuki, F. Koji, N. Akimoto, M. Takashi, S. Toru and O. Atsushi, "A new method of measuring the thumb pronation and palmar abduction angles during opposition movement using a three-axis gyroscope," Journal of Orthopaedic Surgery and Research, vol. 13, 2018.

[13] J. Tang, X. Zhang and L. Zong-Ming, "Operational and maximal workspace of the thumb," Ergonomics, vol. 51, no. 7, p. 11091118,2008

[14] A. Kargov, C. Pylatiuk, M. Jan , S. Schulz and L. Doderlein, "A comparison of the grip force distribution in natural hands and in prosthetic hands," DISABILITY AND REHABILITATION, vol. 26 no. 12, p. 705-711, 2004.

[15] G. G. Akgun, E. Kaplanoglu, A. E. Cetin and O. Ulkir, "Mechanical Design of Exoskeleton for Hand Therapeutic Rehabilitation," Journal of Research in Mechanical Engineering , vol. 4, no. 1, pp. 09-17, 2018.

[16] V. Zamfir and H. Virgolici, "Synthesis of four-bar linkage using displacement equations," Annals of University of Petrosani, Mechanical Engineering, vol. 12, no. 2, pp. 229-234, 2010

[17] C. Cipriani, M. Controzzi and M. C. Carrozza, "Objectives, criteria and methods for the design of the SmartHand transradial prosthesis," Robotica, vol. 28, p. 919-927, 2010.

[18] E. H. Ngale and N. Tsamo , "Manufacturing Cost and Strength Reliability Effects on the Optimal Design of Hand Prosthesis Mechanisms," International Journal of Engineering and Technical Research (IJETR), vol. 6, no. 2, 2016.

[19] C. Lanni and M. Ceccarelli, "An Optimization Problem Algorithm for Kinematic Design of Mechanisms for Two-Finger Grippers," The Open Mechanical Engineering Journal, vol. 3, pp. 49-62, 2009

[20] X. Wang , "The Optimization Design of Six-bar Linkage Mechanism," TELKOMNIKA, vol. 11, no. 7, pp. 4091-4098, 2013.

[21] E. H. Ngale, "Critères de performance et optimisation des mécanismes d'une prothèse de la main," Thèse de philosophiae Doctor (ph.D) en génie mécanique. Ecole Polytechnique de Montréal, Montréal, 1999.

[22] E. H. Ngale and R. Vinet, "Multiobjective optimization of hand prosthesis mechanisms," Mechanism and Machine Theory, vol. 38, no. 1, pp. 3-26, 2003.

[23] E. H. Ngale, A. A. Lakis and R. Vinet, "Optimal synthesis of a planar four-link mechanism used in hand prosthesis," Mechanism and Machine Theory, vol. 36, pp. 1203-1214. , 2001.

[24] R. L. Norton, Design of machinery : An introduction to the synthtesis and Analysis of Mechanisms and Machines, McrawHill, Inc, 1992.

[25] A. H. Galal, A. A. Mohammed and M. L. Maha, "Optimal Synthesis of a 4-Bar Simple Toggle," Journal of American Science, 2011;7(11), vol. 11, no. 7, pp. 522-528, 2011.

[26] I. Demiyanushko, "The Theory of Reliability of Machines and 
Mechanisms - History, State-of-art and Prospects," in 13th World Congress in Mechanism and Machine Science, Guanajuato,México, 2011.

[27] E. Gildemyn, "caracterisation des procedes de fabrication de pieces de securite automobile. optimisation multiobjectifs de la mise en forme," These de Doctorat. École Nationale Supérieure d'Arts et Métiers, France. N: 2008 ENAM 0019, 2008.

[28] R. Dietrich, D. Garsaud, S. Gentillon and M. Nicol, Précis méthode d'usinage. Méthodologie production et Normalisation, Editions AFNOR NATHAN, 1986.

[29] P. Gonzalez, Commande Numérique par calculateur. Tournage/Fraisage/Centres d'usinage, Educalivre. Editions CASTEILLA, 1993.

[30] R. D. Askhedkar and A. A. Dhore, "Synthesis of Four bar mechanism by freudenstein Equation," International Journal of Engineering Research and Applications (IJERA), vol. 2, no. 5, pp. 999-1002, 2012.

[31] Y. Sawaragi, N. Hirotaka and T. Tetsuzo, Theory of multiobjective optimization volume 176, LONDON: Academic Press, Inc. , 1985.

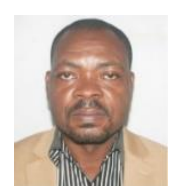

Nestor TSAMO received the postgraduate diploma in pedagogical sciences and Mechanical Engineering , Master Degree in Engineering Sciences, from university of Douala, in 1997, 1999 and 2011 respectively. He is an Assistant lecturer of mechanical Engineering at the College of Technology, of the University of Buea, Cameroon.

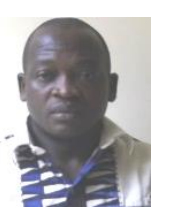

Denis TCHEUKAM TOKO received Ph.D.in Mechanical Engineering from Universiy of Normandie (France) in 1997. Associate Professor and Head of Department of Mechanical Engineering. at the College of Technology, University of Buea. More than 40 papers published.

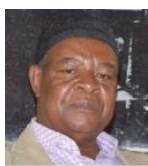

Pierre Kisito TALLA received Ph.D. in Physics. Full Professor. Head of Department of Physics since 2000 at the University of Dschang, Cameroon. More than 60 papers published. 